\title{
Insulin-induced Hypoglycemia Stimulates Corticotropin-releasing Factor and Arginine Vasopressin Secretion into Hypophysial Portal Blood of Conscious, Unrestrained Rams
}

\author{
A. Caraty, ${ }^{\star}$ M. Grino, A. Locatelli, ${ }^{*}$ V. Guillaume, F. Boudouresque, B. Conte-Devolx, and C. Oliver \\ Laboratoire de Neuroendocrinologie Expérimentale, Institut National de la Santé et de la Recherche Médicale U 297, 13326 Marseille, \\ France; and * Laboratoire de Neuroendocrinologie, Physiologie de la Reproduction, Institut National de la Recherche Agronomique, \\ 37380 Nouzilly, France
}

\begin{abstract}
Insulin-induced hypoglycemia (IIH) is a strong stimulator of pituitary ACTH secretion. The mechanisms by which IIH activates the corticotrophs are still controversial. Indeed, in rats the variations of corticotropin-releasing factor (CRF) and arginine vasopressin (AVP) secretion in hypophysial portal blood (HPB) during IIH have been diversely appreciated. This may be due to the stressful conditions required for portal blood collection in rats. We studied the effects of IIH on the secretion of CRF and AVP in HPB and on the release of ACTH and cortisol in peripheral plasma in conscious, unrestrained, castrated rams. After the injection of a low $(0.2 \mathrm{IU} / \mathrm{kg})$ or high dose (2 IU/kg) of insulin, ACTH and cortisol levels in peripheral plasma increased in a dose-related manner. After injection of the low dose of insulin, CRF and AVP secretion in HPB were equally stimulated. After injection of the high dose of insulin, CRF secretion was further stimulated, while AVP release was dramatically increased. These results suggest that when the hypoglycemia is moderate, CRF is the main factor triggering ACTH release, and that the increased AVP secretion potentiates the stimulatory effect of CRF. When hypoglycemia is deeper, AVP secretion becomes predominant and may by itself stimulate ACTH release. (J. Clin. Invest. 1990. 85:1716-1721.) hypothalamic hormones • adrenocorticotropin hormone $\bullet$ cortisol $\bullet$ paraventricular nucleus $\bullet$ stress
\end{abstract}

\section{Introduction}

Insulin-induced hypoglycemia (IIH) ${ }^{1}$ stimulates $\mathrm{ACTH}$ release in man and is frequently used as a provocative test for clinical assessment of disorders of hypothalamic origin (1). However, the mechanisms of this phenomenon and the factors responsible for it are not known. The role of catecholamines of peripheral origin has been recently debated. In one report it was

Part of these data were presented as an abstract at the 71st Annual Meeting of the Endocrine Society.

Address all correspondence to Pr. Charles Oliver, Laboratoire de Neuroendocrinologie Expérimentale, INSERM U.297, Faculté de Médecine Nord, Blvd. P. Dramard, 13326 Marseille Cédex 15, France.

Received for publication 11 October 1989 and in revised form 19 January 1990.

1. Abbreviations used in this paper: CRF, corticotropin-releasing factor; HPB, hypophysial portal blood; IIH, insulin-induced hypoglycemia; PVN, paraventricular nucleus.

J. Clin. Invest.

(c) The American Society for Clinical Investigation, Inc. $0021-9738 / 90 / 06 / 1716 / 06 \$ 2.00$

Volume 85, June 1990, 1716-1721 proposed that IIH stimulates ACTH release by a mechanism in which peripheral catecholamines act directly on the anterior pituitary (2). In another report it was suggested that during IIH the main factors triggering ACTH release were of central rather than peripheral origin, and that circulating catecholamines had no direct action at the pituitary level (3). Indeed, the participation of the hypothalamus in the stimulation of ACTH release during hypoglycemia was substantiated by Plotsky et al. (4), who reported that IIH in rats resulted in no change in hypophysial portal venous corticotropin-releasing factor (CRF) levels, but caused significant increases in arginine vasopressin (AVP) levels. Since they found that immunoneutralization of endogenous CRF could suppress the increase of plasma ACTH levels, they suggested that CRF plays only a permissive role and that AVP is the mediator of hypoglycemia-induced ACTH secretion in the rat. However, the collection of hypophysial portal blood (HPB) in the rat requires major surgery under deep anesthesia with consequent activation of pituitary-adrenocortical hormone secretion (5). Furthermore, sample volumes in rats are restricted because of the size of the animal, and the IIH must be kept constant for at least $60 \mathrm{~min}$ to allow CRF determinations in HPB.

Obviously, studies of the effects of IIH on CRF and AVP release into HPB of unstressed animals would be of much higher physiological relevance. In the sheep, the sampling of HPB is possible in unrestrained and conscious animals (6). We now report the effect of IIH on CRF and AVP release in HPB of conscious, unrestrained, castrated rams.

\section{Methods}

Animals, surgery, and collection of blood samples. The experiments were carried out on seven Romanov rams ( $\sim 50 \mathrm{~kg}$ body weight). The sheep were castrated and prepared for portal blood sampling under general anesthesia, as previously described $(6,7)$. A twin cannula was implanted through the transnasal route in front of the long portal vessels, above the anterior pituitary gland. After $4 \mathrm{~d}$ catheters were inserted into the jugular veins of two animals, placed side by side in two small pens on the floor. $24 \mathrm{~h}$ later one catheter was used for injection of heparin $(25,000 \mathrm{IU}$ at the beginning, followed by $5,000 \mathrm{IU}$ every $30 \mathrm{~min}$ ); the other was connected to a peristaltic pump and used for collection of peripheral blood. At 9:00 a.m. a needle was inserted into the upper cannula to create a lesion of the hypophysial portal vessels, and the resulting portal blood was collected through the lower cannula. Paired samples of portal blood (1-3 ml, depending on the animals) and jugular blood $(2 \mathrm{ml})$ were collected using a peristaltic pump every $10 \mathrm{~min}$ for $4.5 \mathrm{~h}$. The use of catheters and pump ensured minimal disturbance of the animals during sampling, and they appeared to experience little or no stress, as evidenced by frequent rumenation. Subsequently, a bolus of regular porcine insulin $(0.2 \mathrm{IU} / \mathrm{kg})$ was injected intravenously and collection of portal and jugular samples continued for the next $4.5 \mathrm{~h}$. Then, a larger dose of insulin $(2 \mathrm{IU} / \mathrm{kg})$ was injected. Portal and jugular blood were collected for an additional 
period of $\sim 4 \mathrm{~h}$. Blood samples were immediately centrifuged at $4^{\circ} \mathrm{C}$ for $10 \mathrm{~min}$ and the resulting plasma was stored at $-20^{\circ} \mathrm{C}$ until assayed.

Assays. All hormone measurements were performed using radioimmunological techniques. For CRF assay, plasma samples were extracted with $2 \mathrm{vol}$ of acetone. Mean \pm SD recovery after extraction of synthetic CRF added to ovine jugular plasma was $91 \pm 8 \%(n=8)$. Therefore, data were not corrected for the recovery. HPB immunoreactive CRF coeluted with synthetic ovine CRF on HPLC (data not shown). The antiserum used was raised and characterized in our laboratory after immunization of rabbits with synthetic ovine CRF (Bachem, Marina del Rey, CA) coupled to BSA with carbodiimide (6).

Previously described methods were used to measure AVP (8) and ACTH (9) in acetone and polyethyleneglycol plasma extracts, respectively. The radioimmunoassay of cortisol was performed in ethanol plasma extracts using tritiated cortisol (Amersham, Buckinghamshire, $\mathrm{UK}$ ) as tracer and an antiserum that was raised in our laboratory.

The intraassay coefficients of variation within the measurement range of each assay were: CRF, 6\%; ACTH, 5\%; AVP, 5.5\%; and cortisol, $4.7 \%$. The limits of detection of the assays were $5 \mathrm{pg} \mathrm{CRF} / \mathrm{ml}$ plasma, $1.5 \mathrm{pg} \mathrm{AVP} / \mathrm{ml}$ plasma, $5 \mathrm{pg} \mathrm{ACTH} / \mathrm{ml}$ plasma, and $10 \mathrm{mg}$ cortisol/dl plasma.

Glycemia was determined using an automatic glucose analyzer (Beckman Instruments, Inc., Palo Alto, CA) or a reflectance photometer (glucometer; Ames, Paris, France).

Data analysis. The area under the curve for portal CRF and AVP (picograms/milliliter per hour), peripheral ACTH (picograms/milliliter per hour), and cortisol (nanograms/milliliter per hour) was determined according to the trapezoidal rule from plasma hormonal concentrations obtained during three different periods: the hour preceeding the injection of insulin (P1), and the first (P2) and second hours (P3) after the decrease of blood glucose levels below $50 \mathrm{mg} / \mathrm{dl}$. The areas under the curve were calculated for each dose of insulin. All data are expressed as the mean \pm SE. Statistical analysis of the data was made using the unpaired $t$ test.

\section{Results}

Plasma glucose levels. When insulin was given at the dose of $0.2 \mathrm{IU} / \mathrm{kg}$, the onset of hypoglycemia (serum glucose $<50$ $\mathrm{mg} / \mathrm{dl}$ ) occurred $24 \mathrm{~min}$ after insulin injection. The serum glucose nadir was $41 \pm 2 \mathrm{mg} / \mathrm{dl}$ (mean $\pm \mathrm{SE}$ ) and the duration of hypoglycemia (length of time during which serum glucose was $<50 \mathrm{mg} / \mathrm{dl}$ ) was $56 \mathrm{~min}$. After administration of $2 \mathrm{IU}$ insulin/ $\mathrm{kg}$, the onset of hypoglycemia occurred $15 \mathrm{~min}$ after insulin injection and the serum glucose nadir was $29 \pm 2 \mathrm{mg} / \mathrm{dl}$. Hypoglycemia lasted for $>4 \mathrm{~h}$ and the animals did not return spontaneously to euglycemia (Fig. 1).

$A C T H$, cortisol, $C R F$, and AVP levels. In some animals, ACTH and cortisol levels were high during the first 2-h collection, probably related to the onset of the experimental procedure. However, in all animals these levels were stable during the first $\mathbf{2} \mathrm{h}$ preceding the injection of the low dose of insulin (data not shown).

The simultaneous patterns of CRF, AVP, ACTH, and cortisol secretion in two animals during the $4.5 \mathrm{~h}$ before and after the administration of $0.2 \mathrm{IU}$ insulin/ $\mathrm{kg}$ and $\sim 4 \mathrm{~h}$ after the administration of $2 \mathrm{IU}$ insulin/ $\mathrm{kg}$ are shown in Fig. 2. After administration of both the low and high doses of insulin, an increase in portal CRF and AVP levels was observed. It must be noted that the AVP increase was much more accentuated when the high dose of insulin was injected.

As shown on Fig. 3, both ACTH and cortisol secretion increased twofold after injection of the low dose of insulin. Concomitantly, CRF and AVP release in portal blood in-

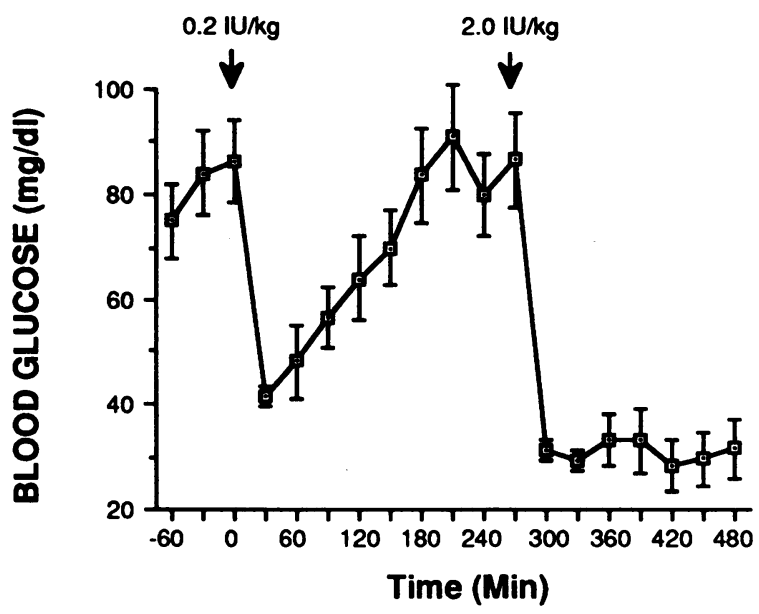

Figure 1. Blood glucose levels before and after IV injection of a low $(0.2 \mathrm{IU} / \mathrm{kg})$ and a high (2 IU/ $/ \mathrm{kg})$ dose of insulin. The timing of insulin injection is indicated by the arrows. Values are the mean \pm SE in seven animals.

creased significantly, 2.9- and 2.8-fold, respectively. The molar CRF/AVP ratio remained stable during the first hour after hypoglycemia. Then a slight but not significant decrease was observed (Fig. 4).

After administration of the high dose of insulin, the release of ACTH and cortisol was further stimulated. ACTH secretion was increased 6.3-fold and cortisol secretion was increased 2.8-fold as compared with the initial preinsulin levels (Fig. 3). Under these conditions, the release of CRF into HPB was also significantly stimulated, reaching values 4.8 times higher than
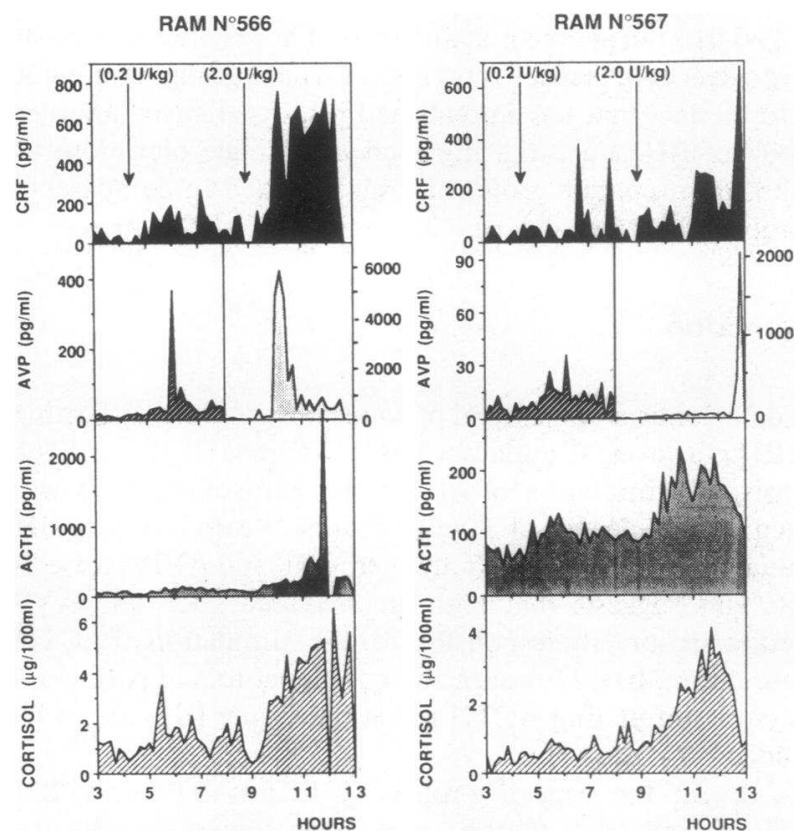

Figure 2. Simultaneous pattern of CRF and AVP secretion into HPB and $A C T H$ and cortisol release into peripheral blood before and after intravenous injection of a low $(0.2 \mathrm{IU} / \mathrm{kg})$ and a high $(2 \mathrm{IU} / \mathrm{kg})$ dose of insulin in two representative animals. The timing of insulin injection is indicated by the arrows. Note the very large increase in portal AVP levels after injection of the high dose of insulin. 

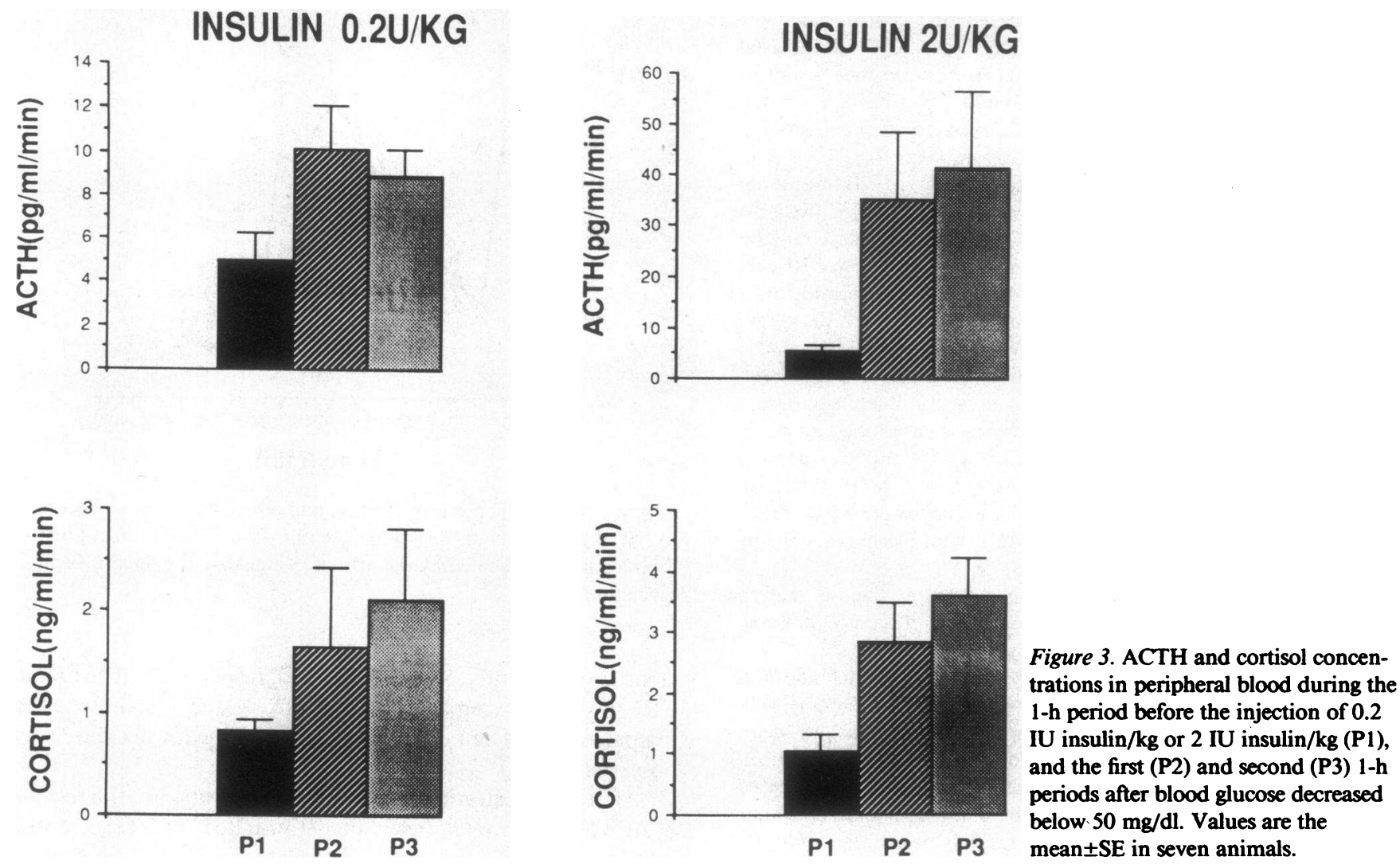

the initial ones. The increased release of AVP was even more pronounced, and its secretion rate increased from 2.6 to 134.9 $\mathrm{pg} / \mathrm{ml}$ per min. As a consequence, the molar CRF/AVP ratio decreased dramatically from $0.42 \pm 0.13$ to $0.039 \pm 0.02$ and $0.052 \pm 0.015$ during the first and second hours after induction of hypoglycemia, respectively (Fig. 5). These changes were not due to the fact that the animals had just experienced another episode of IIH, since the injection of a single high dose of insulin, in a separate group of rams, resulted in comparable variations (data not shown).

\section{Discussion}

Our data confirm and extend previous observations indicating that IIH is a strong stimulator of ACTH release $(1,10-12)$. The intensity of stimulation of ACTH and cortisol secretion was related to the degree of hypoglycemia. We found that IIH stimulated, in a dose-related manner, CRF and AVP release in HPB. This suggests that both an increased CRF and AVP secretion are directly responsible for the stimulation of ACTH release during IIH. However, the additional role of peripheral factors in stimulating ACTH secretion during IIH cannot be excluded.

In the rat, the respective role of CRF and AVP during IIH is still controversial. Plotsky et al. have shown that passive immunization against CRF fully reversed the effects of IIH on plasma ACTH. These authors have also reported that CRF release in HPB was unchanged after insulin injection, while AVP secretion increased. They suggested that CRF plays only a permissive role and that AVP represents the dynamic media-

tor of the IIH-induced ACTH secretion (4). However, Guillaume et al. have recently shown an increased CRF release into HPB after IIH in the rat (5). The experimental designs of Plotsky et al. and Guillaume et al. were similar although not identical. The discrepancy between the two reports may be due to the variable degrees of stress reached by the animals before portal blood collection.

In normal volunteers, De Cherney et al. have reported that the intravenous injection of 1 or $10 \mu \mathrm{g} / \mathrm{kg}$ ovine CRF given at the onset of hypoglycemia does not potentiate the hypoglycemia-induced plasma ACTH response. Their data suggest that the pituitary already receives maximal endogenous CRF stimulation and that CRF secretion is therefore an integral part of the physiological response to hypoglycemia (13). The involvement of factors other than CRF (AVP and peripheral and/or central catecholamines) is not unexpected since in humans the acute response to hypoglycemia is four- to fivefold greater than that to CRF alone. Our data suggest that increases in both CRF and AVP secretion are responsible for the corticotroph stimulation during IIH. Comparable findings have been recently reported by Engler et al. (14). The respective role of CRF and AVP in the ACTH response to IIH in the sheep cannot be deduced from our studies. Indeed, the action of AVP may not be related to its intrinsic activity on pituitary ACTH release, but rather to a potentiation of the effects of CRF on ACTH secretion (for review, see reference 15). This hypothesis is consistent with the blockade by passive immunization against CRF and the partial reduction (33\%) by pretreatment with an AVP antagonist of the IIH-induced ACTH secretion in rats (4). However, after injection of the high dose of insulin, the increased AVP secretion may be sufficient to directly stimulate 

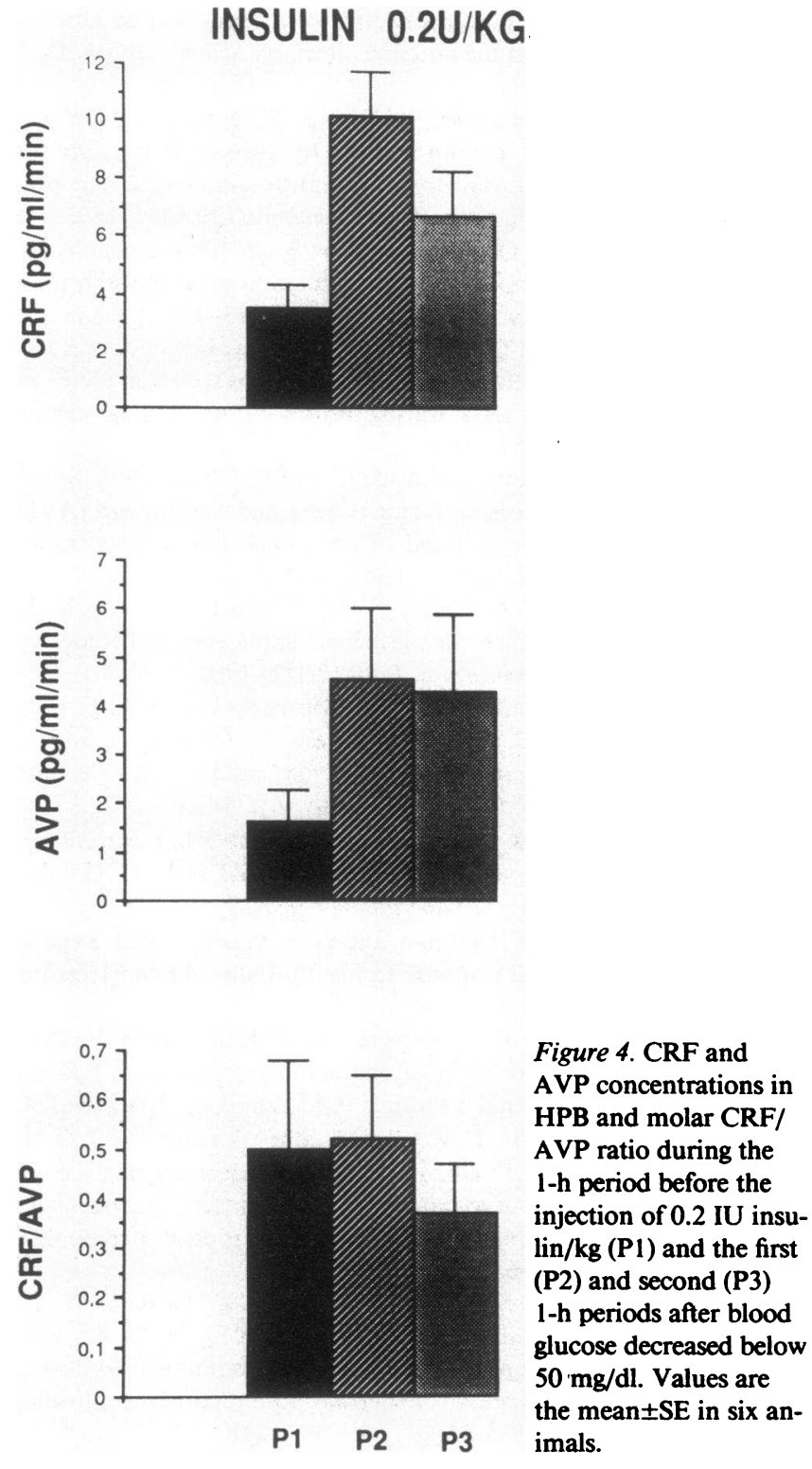

ACTH release. Indeed, AVP is more potent in stimulating the corticotrophs in sheep than in humans and rats. In vivo studies in sheep have shown that CRF and AVP are equipotent in releasing $A C T H$ in the circulation $(16,17)$. In vitro studies have shown that AVP is even more potent than CRF in stimulating ACTH release (18). ACTH measurements during IIH after passive or active immunization against CRF or AVP should be helpful in quantifying the participation of each peptide in the corticotroph stimulation.

CRF released in the long portal vessels derives from fibers originating in cell bodies of the parvocellular part of the hypothalamic paraventricular nucleus (PVN) and abutting the portal primary capillary plexus (19). The source of portal AVP is not completely elucidated. The parvocellular neurons of the PVN may contribute to the AVP recovered in portal blood since AVP is synthetized in CRF neurons. Our knowledge on the differential rate of secretion of CRF and AVP from these neurons is very limited. It has also been suggested that AVP
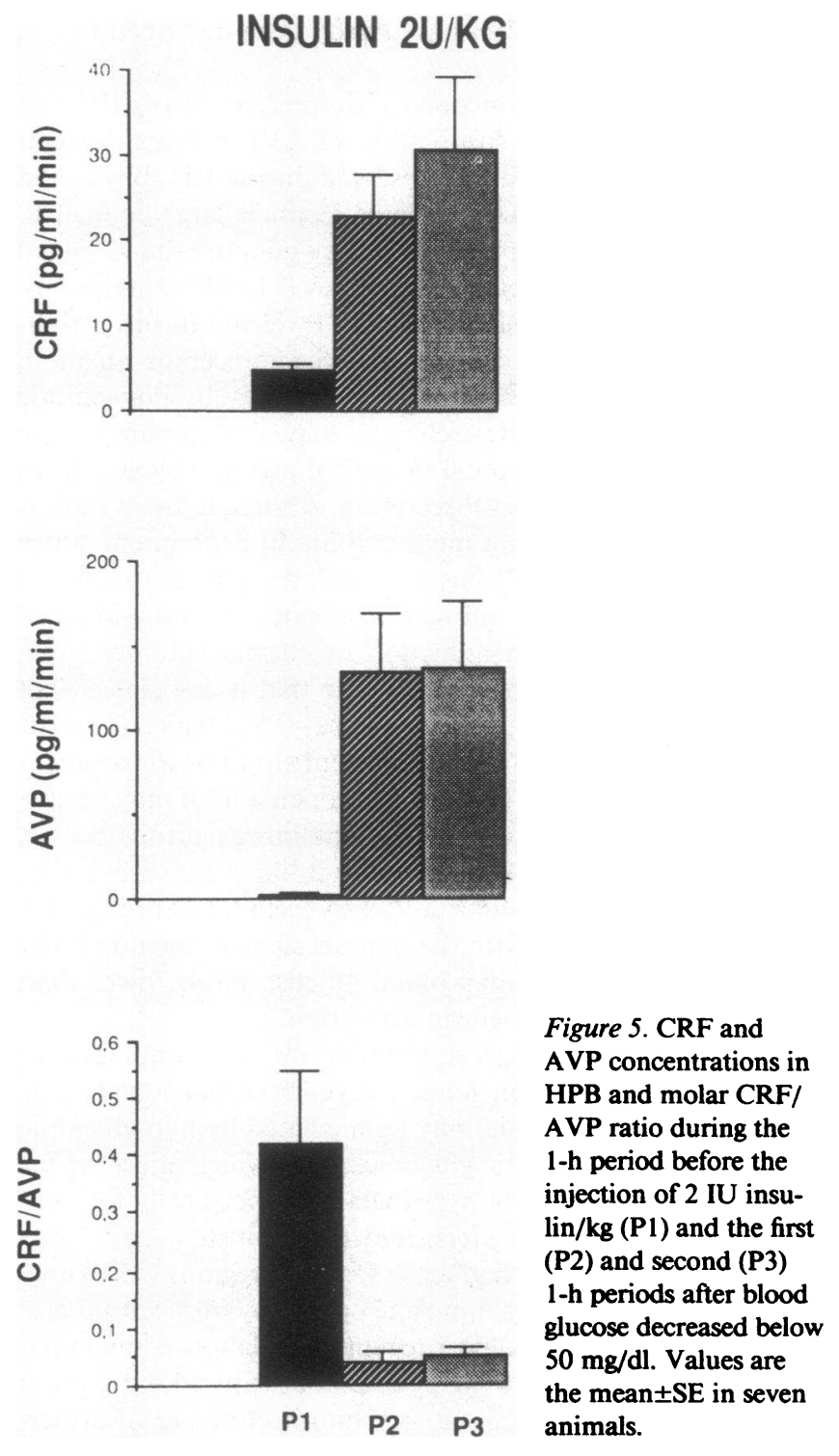

from the magnocellular neurons of the PVN and the supraoptic nucleus can be released at the level of the median eminence (20). The pathways by which magnocellular neurons may release AVP into the hypophysial portal vessels are still undetermined: either direct communication between axons from magnocellular perikarya and the primary portal capillary plexus (21), or retrograde blood flow from the posterior pituitary gland to the median eminence (22). This alternative origin of portal AVP may account for the molar CRF/AVP ratio $<1$ under basal conditions and after the injection of the first dose of insulin. When insulin was injected at the higher dose, the parvocellular neurons of the PVN were probably further stimulated, leading to a further increase of CRF and AVP release. However, under this condition AVP release was much higher than CRF and therefore the CRF/AVP ratio was strikingly lowered. A strong stimulation of the magnocellular neurons may be induced by the marked hypoglycemia reached in the animals. Indeed, an increased AVP release in the periph- 
eral circulation during IIH has already been described in rats (23) and humans (24).

Stimuli other than glucopenia are present during IIH and may participate in the stimulation of AVP release. A slight increase in plasma sodium is observed during IIH. Baylis and Robertson have suggested that this factor is large enough to increase peripheral plasma AVP, but by no more than $2 \mathrm{pg} / \mathrm{ml}$ (23). Its potential effect on portal AVP levels remains unknown. However, IIH stimulated AVP release in the peripheral circulation in one patient with osmoreceptor ablation, indicating that this effect is mediated mainly by nonosmotic stimulation. Hemodynamic changes may also account for the release of AVP. Indeed, a fall in arterial pressure by as little as 5-10\% may stimulate AVP secretion. Although direct indices of blood volume were not measured in our experiment, a rise in hematocrit during IIH has been well described in man and seems to result from a combination of catecholamine-induced hemoconcentration and reduction in plasma volume. However, the reduction in plasma volume that is associated with hypoglycemia has been calculated to be $\sim 5 \%$, which is probably insufficient to act as an independent stimulus to baroregulate AVP release (24). Therefore, glucopenia itself may be able to stimulate the secretion of AVP-containing neurons. So far, it is not known if there is a difference in the effect of hypoglycemia on the magnocellular and parvocellular neurons. Our results are compatible with the hypothesis that magnocellular neuron activation requires blood glucose levels lower than those for parvocellular neuron activation.

The afferent pathways responsible for the stimulation of CRF and AVP secretion have not yet been elucidated. The response to hypoglycemia may be mediated by hypothalamic and/or extrahypothalamic glucoreceptors, which affect the firing of PVN neurons. The hypothalamus, specifically the ventromedial and lateral centers, and the brainstem have been proposed to contain such glucose-sensitive regions (25). However, reversal of hypothalamic glucopenia by intracarotid glucose infusion, which would prevent stimulation of hypothalamic glucose receptors by hypoglycemia, reduced but did not abolish the ACTH response to insulin injection (12). Furthermore, lateral hypothalamic deafferentation reduced by only $30 \%$ the corticosteroid response to 2-deoxyglucose injection (26). These observations suggest that the IIH-induced CRF and AVP release into HPB is mediated through extrahypothalamic pathways. We and others have shown recently that central catecholamines, originating from the brainstem nuclei, have a stimulatory effect on hypothalamic CRF secretion in the rat $(27,28)$. Interestingly, hypothalamic norepinephrine activity is increased during IIH in rats, and this increase parallels the variation in plasma corticosterone (29). Thus, it can be proposed that an increase in central catecholaminergic activity may be responsible for the stimulation of hypothalamic CRF and AVP secretion during IIH.

\section{References}

1. Watabe, T., K. Tanaka, M. Kumagae, S. Itoh, F. Takeda, K. Morio, M. Hasegawa, T. Horiuchi, S. Miyabe, and N. Shimizu. 1987. Hormonal responses to insulin-induced hypoglycemia in man. J. Clin. Endocrinol. Metab. 165:1187-1191.

2. Mezey, E., T. D. Reisine, M. J. Brownstein, M. Palkovits, and J.
Axelrod. 1984. $\beta$-Adrenergic mechanism of insulin-induced adrenocorticotropin release from the anterior pituitary. Science (Wash. DC). 226:1085-1087.

3. Jezova, D., R. Kvetnansky, K. Kovacs, Z. Oprsalova, M. Vigas, and G. B. Makara. 1987. Insulin-induced hypoglycemia activates the release of adrenocorticotropin predominantly via central and propranolol insensitive mechanisms. Endocrinology. 120:409-415.

4. Plotsky, P. M., T. O. Bruhn, and W. Vale. 1985. Hypophysiotropic regulation of adrenocorticotropin secretion in response to insulin-induced hypoglycemia. Endocrinology. 117:323-329.

5. Guillaume, V., M. Grino, B. Conte-Devolx, F. Boudouresque, and C. Oliver. 1989. Corticotropin-releasing factor secretion increases in rat hypophysial portal blood during insulin-induced hypoglycemia. Neuroendocrinology. 49:676-679.

6. Caraty, A., M. Grino, A. Locatelli, and C. Oliver. 1988. Secretion of corticotropin releasing factor (CRF) and vasopressin (AVP) into the hypophysial portal blood of conscious, unrestrained rams. Biochem. Biophys. Res. Commun. 155:841-849.

7. Locatelli, A., and A. Caraty. 1987. Approche transnasale du système porte-hypophysaire chez le bélier: application à l'étude des neuro-sécrétions. Sci. Tech. Anim. Lab. 12:185-190.

8. Giaufre, E., B. Conte-Devolx, G. Morisson-Lacombe, F. Boudouresque, M. Grino, B. Rousset-Rouvière, V. Guillaume, and C. Oliver. 1985. Anesthésie péridurale par voie caudale chez l'enfant: étude des variations endocriniennes. Presse Méd. 14:201-203.

9. Usategui, R., C. Oliver, H. Vaudry, G. Lombardi, I. Rozenberg, and A. M. Mourre. 1976. Immunoreactive $\alpha-M S H$ and ACTH levels in rat plasma and pituitary. Endocrinology. 98:189-196.

10. Karteszi, M., M. F. Dallman, and G. B. Makara. 1982. Regulation of the adrenocortical response to insulin-induced hypoglycemia. Endocrinology. 111:535-541.

11. Keller-Wood, M. E., J. Shinsako, L. C. Keil, and M. F. Dallman. 1981. Insulin-induced hypoglycemia in conscious dogs. I. Doserelated pituitary and adrenal responses. Endocrinology. 109:818-824.

12. Keller-Wood, M. E., C. E. Wade, J. Shinsako, L. C. Keil, G. R. Van Loon, and M. F. Dallman. 1982. Insulin-induced hypoglycemia in conscious dogs: effect of maintaining carotid arterial glucose levels on the adrenocorticotropin, epinephrine and vasopressin responses. Endocrinology. 112:624-632.

13. De Cherney, G. S., C. R. De Bold, R. V. Jackson, W. R Sheldon, Jr., T. C. Kamilaris, D. P. Island, and D. N. Orth. 1987. Effect of ovine corticotropin-releasing hormone administered during insulin-induced hypoglycemia on plasma adrenocorticotropin and cortisol. J. Clin. Endocrinol. Metab. 64:1211-1218.

14. Engler, D., T. Pham, M. J. Fullerton, G. Ooi, J. W. Funder, and I. J. Clarke. 1989. Studies of the secretion of corticotropin-releasing factor and arginine vasopressin into the hypophysial-portal circulation of the conscious sheep. I. Effect of an audiovisual stimulus and insulin-induced hypoglycemia. Neuroendocrinology. 49:367-381.

15. Tilders, F. J., F. Berkenbosch, I. Vermes, E. A. Linton, and P. G. Smelik. 1985. Role of epinephrine and vasopressin in the control of the pituitary-adrenal response to stress. Fed. Proc. 44:155-160.

16. Redekopp, C. A., J. H. Livesey, A. Toth, and R. A. Donald. 1985. Effect of ovine corticotropin releasing factor and arginine vasopressin on ACTH and aldosterone secretion in sheep. Horm. Metab. Res. 17:428-429.

17. Pradier, P., M. J. Davicco, and A. Safwate. 1986. Plasma adrenocorticotrophin, cortisol and aldosterone responses to ovine corticotrophin-releasing factor and vasopressin in sheep. Acta Endocrinol. 111:93-100.

18. Familari, M., A. I. Smith, R. Smith, and J. W. Funder. 1989. Arginine vasopressin is a much more potent stimulus to ACTH release from ovine anterior pituitary cells than ovine corticotropin-releasing factor. I. In vitro studies. Neuroendocrinology. 50:152-157.

19. Kiss, J. Z. 1988. Dynamism of chemoarchitecture in the hypothalamic paraventricular nucleus. Brain Res. Bull. 20:699-708. 
20. Holmes, M. C., F. A. Antoni, G. Aguilera, and K. J. Catt. 1986. Magnocellular axons in passage through the median eminence release vasopressin. Nature (Lond.). 319:326-329.

21. Baertschi, A. J. 1980. Portal vascular route from hypophysial stalk/neural lobe to adenohypophysis. Am. J. Physiol. 239:R463R469.

22. Oliver, C., R. S. Mical, and J. C. Porter. 1977. Hypothalamicpituitary vasculature: evidence for retrograde blood flow in the pituitary stalk. Endocrinology. 101:598-604.

23. Baylis, P. H., and G. L. Robertson. 1980. Rat vasopressin response to insulin-induced hypoglycemia. Endocrinology. 107:19751979.

24. Baylis, P. H., R. L. Zerbe, and G. L. Robertson. 1981. Arginine vasopressin response to insulin-induced hypoglycemia in man. J. Clin. Endocrinol. Metab. 53:935-939.

25. Oomura, Y. 1983. Glucose as a regulator of neuronal activity. Adv. Metab. Disord. 10:32-65.
26. Sun, C. L., N. B. Thoa, and I. J. Kopin. 1979. Comparison of the effects of 2-deoxyglucose and immobilization on plasma levels of catecholamines and corticosterone in awake rats. Endocrinology. 105:306-311.

27. Szafarczyk, A., G. Alonso, G. Ixart, F. Malaval, and I. Assenmacher. 1985. Diurnal-stimulated and stress-induced ACTH release in rats is mediated by ventral noradrenergic bundle. Am. J. Physiol. 249:E219-E226.

28. Guillaume, V., B. Conte-Devolx, A. Szafarczyk, F. Malaval, N. Pares-Herbute, M. Grino, G. Alonso, I. Assenmacher, and C. Oliver. 1987. The corticotropin-releasing factor release in rat hypophysial portal blood is mediated by brain catecholamines. Neuroendocrinology. 46:143-146.

29. Smythe, G. A., J. E. Bradshaw, M. V. Nicholson, H. S. Grunstein, and L. H. Storlien. 1985. Rapid bidirectional effects of insulin on hypothalamic noradrenergic and serotoninergic neuronal activity in the rat: role of glucose homeostasis. Endocrinology. 117:1590-1597. 